\title{
ANALYZING THE EFFECT OF DENSITY VALUE DEVIATION ON PRINT QUALITY
}

\section{ANALISIS PENGARUH PENYIMPANGAN NILAI DENSITAS TERHADAP KUALITAS HASIL CETAK}

\author{
Soebardianto $^{\text {a }}$, Septia Ardiani ${ }^{a^{*}}$, Romi Setiawan ${ }^{\mathrm{a}}$ \\ aTeknik Grafika, Politeknik Negeri Media Kreatif, Indonesia \\ *Email: septiaardiani@polimedia.ac.id
}

\begin{abstract}
The quality control activities, in particular the measurement of density values, are part of the quality control parameters carried out by each company. Companies sometimes forget about the quality parameters of the name, even though the quality can give the printed products a good guarantee in the eyes of consumers. To achieve the quality level, of course, the business does not stand idle, there are several things that need to be done or provided by the business to support the quality, namely man (human), machine (machine), material (material), and method (method). In the development of technology in an increasingly advanced digital world, companies want to continue to compete with a digital world by making inroads, this of course gives the products produced by the company a good or a good level of quality. In this discussion, there is an identification of problematic aspects arising from the deviation of density values as well as ways to obtain standard density values and factors that affect the quality of prints on book cover prints using a Heidelberg machine.
\end{abstract}

\section{Keywords - Quality Control, Density, Standart, Product, Deviation}

\begin{abstract}
Abstrak - Kegiatan quality control khususnya pengukuran nilai density merupakan salah satu dari parameter pengendalian kualitas yang dilakukan oleh setiap perusahaan. Perusahaan terkadang melupakan yang namanya parameter kualitas padahal dengan adanya kualitas dapat menjadikan produk yang dicetak mempunyai jaminan yang bagus dimata konsumen. Untuk mendapatkan standar dari kualitas tentunya perusahaan tidak berdiam saja, ada beberapa hal yang perlu dilakukan atau disediakan oleh perusahaan untuk dapat menunjang kualitas, yaitu man (manusia), machine (mesin), material (bahan), dan methode (metode). Dalam perkembangan teknologi di dunia digital yang semakin maju tentunya perusahaan ingin tetap bersaing dengan dunia yang serba digital dengan melakukan terobosan-terobosan tersebut, hal itu tentunya membuat produk yang dihasilkan oleh perusahaan mempunyai tingkat kualitas
\end{abstract}


yang baik atau bagus. Dalam pembahasan ini terdapat identifikasi aspek permasalahan yang timbul dari penyimpangan nilai density serta cara untuk mendapatkan nilai density yang standar dan faktor yang mempengaruhi kualitas hasil cetak pada cetakan Cover Buku menggunakan mesin Heidelberg.

Kata Kunci-Quality control, Densitas, Standar, Produk, Penyimpangan

\section{PENDAHULUAN}

Seiring dengan perkembangan teknologi, industri grafika juga berkembang semakin pesat di tengah masyarakat. Masih banyak produk-produk grafika yang masih sangat dibutuhkan masyarakat sampai saat ini diantaranya cetakan kantor, cetakan komersial, cetakan berharga (security printing), dan cetakan kemasan. Industri grafika terus berkembang mengikuti perkembangan zaman, terbukti dengan adanya pembaruan-pembaruan pada teknologi, mesin, serta sistem dan metode yang digunakan dalam penerapan langsung pada mesin cetak ofset. Mesin-mesin yang digunakan di grafika sudah banyak beralih menggunakan teknologi digital meskipun ada beberapa industry yang masih mempertahankan mesin konvensional.

Penggunaan teknologi digital yang dilakukan oleh perusahaan tidak lepas dari kepuasan konsumen dan produk yang dihasilkannya. Konsumen pasti berharap bahwa produk yang dibeli memiliki kualitas yang baik. Menurut Soebardianto (2017), kualitas adalah hal yang fundamental, menjadi fondasi bagi daya jual produk yang menentukan penerimaan konsumen akan produk ataupun penerimaan publik terhadap brand suatu perusahaan. Kualitas yang baik, akan menghasilkan kepuasan konsumen terhadap produk suatu perusahaan. Kepuasan merupakan cikal bakal timbulnya rasa loyalitas konsumen terhadap produk dan brand perusahaan sehingga akan menimbulkan kepercayaan dan pembelian yang berkelanjutan. Tumbuhnya loyalitas pada pelanggan memberikan dampak positif bagi sebuah bisnis. Dalam jangka panjang, loyalitas dari pelanggan akan menguntungkan. Sebagai contoh, pelanggan bersedia membayar harga lebih tinggi, dan pelanggan bersedia merekomendasikan ke pelanggan yang baru.

Dalam grafika ada tiga bagian utama yang tidak dapat dipisahkan dalam proses pengerjaannya, yaitu bagian pracetak, cetak dan penyelesaian. Bagian pracetak mempersiapkan file hingga pelat cetak yang akan dicetak, proses tersebut dari pengerjaan 
desain, imposisi halaman, proofing, hingga proses pembuatan pelat. Hasil akhir dari pekerjaan dibagian pracetak adalah pelat cetak. Bagian cetak melakukan proses pencetakan produk secara massal dengan acuan cetak yang dialihkan kebahan cetak yaitu kertas, dimana pada pelat bagian image area terdapat tinta sedangkan pada bagian non image area tidak terdapat tinta, untuk dapat tercetak pada kertas memerlukan kain karet sebagai media penghubung ke kertas dengan dibantu oleh silinder tekan (Sudiyamto dan Sutiyo, 2011). Hasil akhir dari pekerjaan dibagian cetak adalah lembaran yang sudah tercetak. Bagian paska cetak adalah bentuk jadi hasil cetak seperti buku, majalah dan kemasan.

Agar produk cetak yang dihasilkan memiliki kualitas yang baik, maka kualitas pada setiap tahapan perlu diperhatikan dan dilakukan pengendalian, pengendalian pada proses cetak dilakukan langsung oleh operator sesuai dengan pekerjaannya masingmasing. Operator mengendalikan kualitas hasil cetak salah satunya menggunakan alat ukur untuk mendapatkan nilai densitas. Densitas adalah kepekatan tinta di atas kertas yang diperoleh dari hasil cetak. Nilai densitas diperoleh dengan cara mengukur bidang solid pada colour bar, selain itu hal yang perlu diperhatikan dalam proses cetak adalah printing condition yang ada, dimana printing condition meliputi jenis kertas yang digunakan, tinta cetak yang dipakai, raster yang digunakan dan lain sebagainya (Subardianto, 2017).

Parameter dari cetakan yang berkualitas salah satunya dapat dilihat dari konsistensi warna yang dihasilkan pada setiap lembar cetakan, tetapi permasalahan yang ada banyak perusahaan dan operator cetak yang masih belum mampu menghasilkan dan menjamin bahwa cetakan yang dihasilkan memiliki konsistensi warna yang baik sehingga kualitas yang dihasilkan belum dapat dikatakan sempurna. Jika pun ada operator yang dirasa sudah cukup baik keterampilan mencetaknya, tetapi belum tentu operator mengerti bagaimana mengendalikan konsistensi warna pada cetakannya dengan baik dan benar. Maka dari itu, perlu dilakukan analisis pengaruh penyimpangan nilai densitas terhadap kualitas hasil cetak kemasan.

\section{METODE}

Produk cetak yang diobservasi adalah sampul buku dengan spesifikasi detail sebagai berikut: dicetak pada tanggal 28 Febuari 2018 dengan oplah (cetak baik) sebanyak 4000 eksemplar (4230 eksemplar). Jenis Kertas yang digunakan Art Carton 230 gram dengan ukuran kertas 36 x $26 \mathrm{~cm}$ dan ukuran jadi 15,2 x $23 \mathrm{~cm}$. Warna yang digunakan 4/0 tinta 
Cemani Toka. Untuk jenis mesin yang digunakan adalah mesin Heidelberg Print Master dan alat ukurnya densitometer X-Rite Exact.

Proses pengendalian kualitas dilakukan oleh operator cetak salah satunya dalam pengukuran nilai densitas warna proses dan khusus. Pengukuran nilai densitas dilakukan untuk mengetahui tingkat konsistensi warna proses dan khusus pada saat proses pencetakan berlangsung sehingga menghasilkan warna yang tidak terlalu menyimpang, sehingga hasil dari setiap pencetakan mempunyai kualitas yang mendekati baik. Langkah-langkah yang dilakukan dalam proses pengukuran nilai densitas, sebagai berikut:

1. Mencari tempat mengukur yang rata atau datar dengan dialasi kertas berwarna putih.

2. Menyiapkan alat ukur densitomer.

3. Mengambil hasil cetakan dari unit pengeluaran atau delivery unit.

4. Melakukan proses pengukuran pada bagaian color bar, dengan mengatur proses pengukuran khusus untuk densitas.

5. Mengarahkan alat densitometer ke bagian solid densitas dan menekankan densitometer tersebut, nilai densitas akan muncul pada layar.

6. Mengambil sampel hasil cetakan setiap cetakan dengan kelipatan 200 eksemplar dan seterusnya sampai selesai untuk diukur nilai densitas tersebut.

7. Setelah mendapatkan nilai densitas dari pengukuran, selanjutnya angka-angka nilai densitas dimuat dalam tabel hasil pengukuran bersama, untuk dapat dilihat penyimpangan yang terjadi pada cetakan tersebut.

Dalam mendapatkan standar pengukuran nilai densitas dilakukan proses pengukuran terlebih dahulu pada sampul buku dengan interval 500 lembar dan merataratakan hasil pengukuran tersebut sehingga didapat hasil standar dari proses pengukuran, sebagai berikut:

Tabel 1. Hasil Pengukuran Desnistas Standar

\begin{tabular}{|c|c|}
\hline \multicolumn{2}{|c|}{ STANDAR DENSITY } \\
\hline WARNA & Density \\
\hline $\mathrm{C}$ & 1,30 \\
\hline $\mathrm{M}$ & 1,47 \\
\hline $\mathrm{Y}$ & 1,08 \\
\hline $\mathrm{K}$ & 1,68 \\
\hline
\end{tabular}

\section{HASIL DAN PEMBAHASAN}

Perbedaan nilai densitas akan mengakibatkan terjadinya perbedaan warna. Semakin tinggi nilai densitas maka warnanya akan semakin solid atau gelap dan nilai $\mathrm{L}^{*}$ (Lightness) akan turun kecerahannya, sementara sebaliknya nilai densitas rendah maka warna akan pudar atau menipis dan nilai 
L* (Lightness) akan semakin cerah (Subardianto, 2017).

Faktor yang mempengaruhi kualitas hasil cetak, ada empat yaitu man, machine, material dan methode. Pertama man, operator adalah faktor yang paling menentukan, karena pada bagian cetak proses pengendalian kualitas cetak dilakukan oleh manusia (operator) dengan mempunyai keterampilan khusus dan keahlian yang memumpuni sangat berpengaruh dalam mengatasi masalah serta melakukan pengendalian pada setiap proses cetak. Operator dengan skill yang baik akan membantu sekali dalam pencapaian kualitas hasil cetak yang standar, karena operator tersebut tentunya paham betul setiap prosedur langkah kerja yang harus dilakukan dan ketelitian serta kecermatan dalam mengendalikan setiap lembar cetak. Akan tetapi pada kenyataannya di industri tidak semua operator mampu mengendalikan kualitas dengan baik masih terdapat beberapa operator yang belum memahami betul mengenai parameter pengendalian kualitas agar cetakan yg dihasilkan mempunyai kualitas tentunya karena tidak didukung dengan skill atau keterampilan yang memumpuni.

Kedua, mesin sangat diperlukan oleh setiap perusahaan yang bergerak di bidang manufacture terkhusus industri grafika, karena penggunaan mesin akan membawa kemudahan dalam proses produksi dan menghasilkan keuntungan yang lebih besar serta membantu meningkatkan efisiensi kerja. Untuk memiliki produk-produk berkualitas yang akan berpengaruh dalam produktivitas yang lebih tinggi dalam setiap unit kerja, perusahaan perlu menggunakan mesin canggih dengan kondisi yang baik dan mekanik yang memiliki berbagai macam keahlian serta penyetelan atau setting pada mesin yang sesuai dan standar. Akan tetapi pada kenyataannya di industri tidak semua mesin memiliki kondisi yang baik untuk menunjang produktivitas kerja, karena sering terjadi hal-hal yang diakibatkan oleh mesin yang berakibat kualitas tidak tercapai dengan baik seperti pada bagian pemasukan atau feeder unit sering mengalami masalahmasalah dalam proses jalannya kertas dan mesin sering mati atau tidak berjalan lancar.

Ketiga material, bahan digunakan sebagai bahan dasar untuk proses produksi, pemilihan bahan yang tepat untuk memenuhi batas toleransi yang diinginkan itu juga sangat tepat. Material yang berperan dalam kualitas ada tiga, yaitu kertas (gramatur, ketebalan, kesikuan potong, arah serat, kondisi kertas, kelembaban, dan warna $\mathrm{L} * \mathrm{a} * \mathrm{~b} *$ kertas), air pembasah (prosentase, $\mathrm{pH}$, conductivity, dan temperatur) dan tinta (tipe warna : $\mathrm{L}^{*} \mathrm{a}^{*} \mathrm{~b}^{*}$, color strenght, tack, daya alir, kekentalan, dan pengeringan). Akan 
tetapi pada kenyataannya di industri tidak semua bahan yang digunakan sesuai dengan standar untuk menunjang kualitas. Industri biasanya lebih mengutamakan order-order yang bersifat penting seperti order buku departement pendididikan nasional, order dari kpu dan lain sebagainya yang dianggap perlu menggunakan bahan-bahan yang standar agar tercapainya kualitas dan dapat memuaskan konsumen, berbeda dengan order yang tidak dianggap perlu menggunakan bahan-bahan standar, industri hanya ingin membuat konsumen puas dengan hasil produknya tanpa melihat dari segi standar yang ada.

Keempat metode, dalam menciptakan produk dan layanan yang berkualitas, maka metode informasi modern sudah harus dikuasai atau diterapkan oleh perusahaan. Metode informasi modern yang membantu dalam penyimpanan dan mengambil data yang diperlukan untuk pembuatan, pemasaran, dan pelayanan. Akan tetapi pada kenyataannya di industri tidak semua metode berjalan dengan lancar, sering terjadi kekeliruan dalam proses produksi, sistem pengelolaan order dan sistem pengendalian kualitas. Hal itu dapat mengakibatkan standar kualitas yang semestinya dapat tercapai dengan baik menjadi terganggu karena halhal tersebut.

Gambar grafik pengukuran densitas di samping menghasilkan tingkat presisi, yang menunjukkan seberapa dekat serangkaian pengukuran satu sama lain dan mengetahui tingkat penyimpangan yang terjadi dalam setiap pengukuran interval 500 lembar.

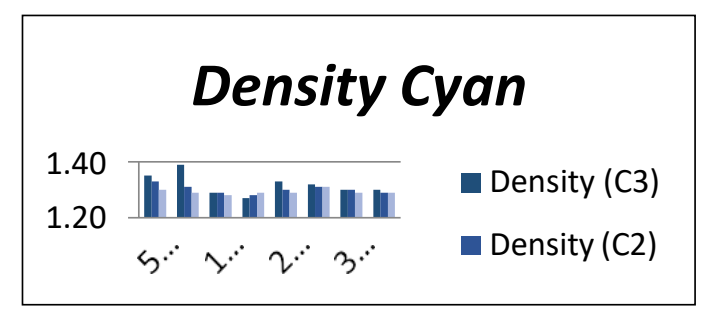

(a)

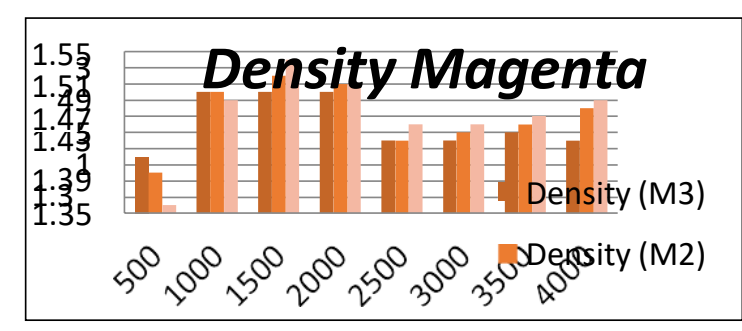

(b)

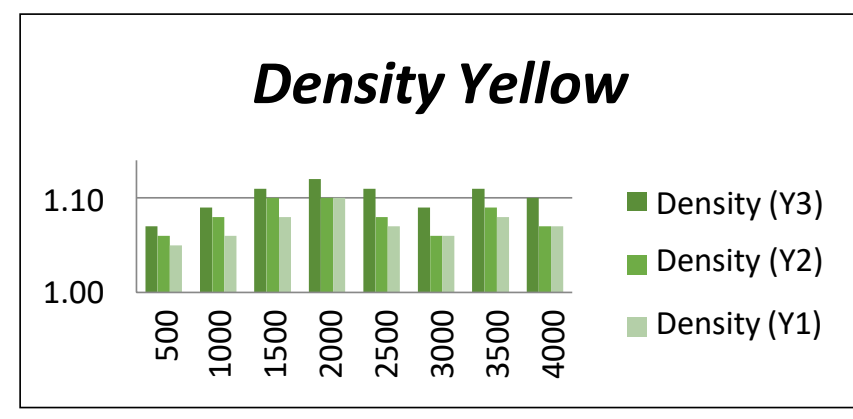

(c)

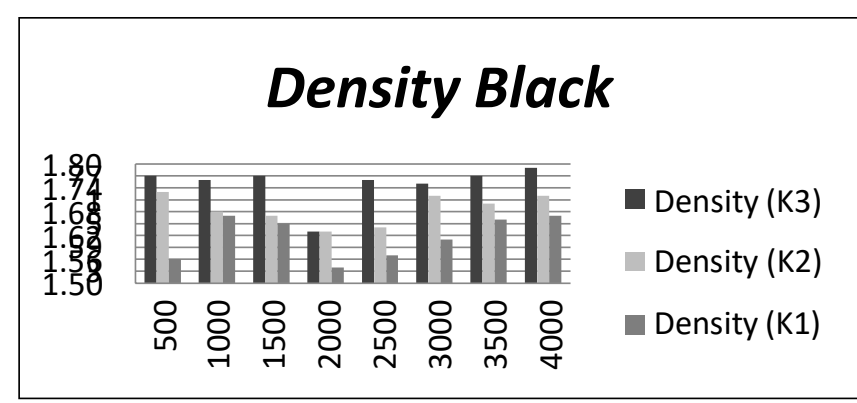

(d)

Gambar 1. Grafik Hasil Pengukuran Densitas Untuk mengetahui selisih yang terjadi dalam setiap cetakan, digunakan rumus (Nurjalih, 2010): 
Selisih penyimpangan nilai densitas

$$
=\mathrm{D}^{2}-\mathrm{D}^{1}
$$

Keterangan: $\mathrm{D}^{2}$ : Density Sample

$$
\mathrm{D}^{1} \text { : Density Standar }
$$

Berikut selisih dari hasil pengukuran nilai densitas yang terjadi pada masingmasing warna proses:

\section{Warna Cyan}

a. Lembar cetakan ke-500

$\mathrm{C} 1$ (Kanan), $\mathrm{D}^{2}-\mathrm{D}^{1}=1,30-1,30=0,00$

$\mathrm{C} 2$ (Tengah), $\mathrm{D}^{2}-\mathrm{D}^{1}=1,33-1,30=0,03$

$\mathrm{C} 3$ (Kiri), $\mathrm{D}^{2}-\mathrm{D}^{1}=1,35-1,30=0,05$

Jadi, terlihat penyimpangan pada bagian lembar cetak sisi tengah dan kiri dibanding sisi kanan yang tidak mengalami penyimpangan atau sesuai dengan standar. Dengan demikian pada sisi yang mengalami penyimpangan perlu mengatur pengurangan tinta yang diberikan pada cetakan.

b. Lembar cetakan ke - 1000

$\mathrm{C} 1$ (Kanan), $\mathrm{D}^{2}-\mathrm{D}^{1}=1,29-1,30=-0,01$

$\mathrm{C} 2$ (Tengah), $\mathrm{D}^{2}-\mathrm{D}^{1}=1,31-1,30=0,01$

C3 (Kiri), $\mathrm{D}^{2}-\mathrm{D}^{1}=1,39-1,30=0,09$

Jadi, terlihat penyimpangan pada semua bagian lembar cetak sisi kanan, tengah dan kiri. Dengan demikian pada sisi bagian kanan perlu penambahan tinta yang sedikit sedangkan sisi tengah dan kiri perlu mengatur pengurangan tinta yang diberikan pada cetakan.

c. Lembar cetakan ke - 1500
$\mathrm{C} 1$ (Kanan), $\mathrm{D}^{2}-\mathrm{D}^{1}=1,28-1,30=-$ 0,02

C2 (Tengah), $\mathrm{D}^{2}-\mathrm{D}^{1}=1,29-1,30=-$ 0,01

$\mathrm{C} 3$ (Kiri), $\mathrm{D}^{2}-\mathrm{D}^{1}=1,29-1,30=-0,01$

Jadi, terlihat penyimpangan pada semua bagian lembar cetak sisi kanan, tengah dan kiri. Dengan demikian pada sisi bagian kanan, tengah dan kiri perlu mengatur sedikit penambahan tinta yang diberikan pada cetakan.

d. Lembar cetakan ke -2000

$\mathrm{C} 1$ (Kanan), $\mathrm{D}^{2}-\mathrm{D}^{1}=1,29-1,30=-$ 0,01

C2 (Tengah), $\mathrm{D}^{2}-\mathrm{D}^{1}=1,28-1,30=-$ 0,02

C3 (Kiri), $\mathrm{D}^{2}-\mathrm{D}^{1}=1,27-1,30=-0,03$

Jadi, terlihat penyimpangan pada semua bagian lembar cetak sisi kanan, tengah dan kiri. Dengan demikian pada sisi bagian kanan, tengah dan kiri perlu mengatur sedikit penambahan tinta yang diberikan pada cetakan.

e. Lembar cetakan ke -2500

$\mathrm{C} 1($ Kanan $), \mathrm{D}^{2}-\mathrm{D}^{1}=1,29-1,30=-$ 0,01

C2 (Tengah), $\mathrm{D}^{2}-\mathrm{D}^{1}=1,30-1,30=0,00$

$\mathrm{C} 3$ (Kiri), $\mathrm{D}^{2}-\mathrm{D}^{1}=1,33-1,30=0,03$

Jadi, terlihat penyimpangan pada bagian lembar cetak sisi kanan, dan kiri dibanding sisi tengah yang tidak mengalami penyimpangan atau sesuai 
dengan standar. Dengan demikian pada sisi bagian kanan perlu mengatur sedikit penambahan tinta, sedangkan bagi sisi kiri mengatur sedikit pengurangan tinta yang diberikan pada cetakan.

f. Lembar cetakan ke -3000

C1 (Kanan), $D^{2}-D^{1}=1,31-1,30=0,01$

C2 (Tengah), $\mathrm{D}^{2}-\mathrm{D}^{1}=1,31-1,30=0,01$

C3 (Kiri), $D^{2}-D^{1}=1,32-1,30=0,02$

Jadi, terlihat penyimpangan pada semua bagian lembar cetak sisi kanan, tengah dan kiri. Dengan demikian pada sisi bagian kanan, tengah dan kiri perlu mengatur sedikit pengurangan tinta yang diberikan pada cetakan.

g. Lembar cetakan ke -3500

$\mathrm{C} 1$ (Kanan), $\mathrm{D}^{2}-\mathrm{D}^{1}=1,29-1,30=-$ 0,01

C2 (Tengah), $\mathrm{D}^{2}-\mathrm{D}^{1}=1,30-1,30=0,00$

$\mathrm{C} 3$ (Kiri), $\mathrm{D}^{2}-\mathrm{D}^{1}=1,30-1,30=0,00$

Jadi, terlihat penyimpangan pada bagian lembar cetak sisi kanan, sedangkan pada sisi tengah dan kiri sudah sesuai dengan standar. Dengan demikian pada sisi bagian kanan perlu mengatur sedikit penambahan tinta yang diberikan pada cetakan.

h. Lembar cetakan ke -4000

C1 (Kanan), $\mathrm{D}^{2}-\mathrm{D}^{1}=1,29-1,30$

$=-0,01$

C2 (Tengah), $\mathrm{D}^{2}-\mathrm{D}^{1}=1,29-1,30$

$=-0,01$
C3 (Kiri), $\mathrm{D}^{2}-\mathrm{D}^{1}=1,30-1,30=0,00$

Jadi, terlihat penyimpangan pada bagian lembar cetak sisi kanan dan tengah, sedangkan pada bagian kiri sesuai dengan standar. Dengan demikian pada sisi bagian kanan dan tengah perlu mengatur sedikit penambahan tinta yang diberikan pada cetakan.

2. Warna magenta, yellow, dan black. Dengan menggunakan rumus perhitungan yang sama dengan cyan didapatkan bahwa untuk warna magenta, yellow, dan black terlihat penyimpangan pada semua bagian lembar cetak sisi kanan, tengah dan kiri. Densitas magenta dengan standar magenta 1,47 hanya terjadi pada lembar cetak ke- 3500 (sisi kanan) yang nilai densitasnya sama dengan standar, selain dari itu nilainya hanya sebatas toleransi bahkan melebihi dari toleransi pada cetakan ke- 500 (sisi kanan dan tengah) dengan penyimpangan nilai densitas -0,11 dan -0,07, cetakan ke- 1500 (sisi kanan) dengan penyimpangan nilai densitas 0,07. Nilai densitas yellow dengan standar yellow 1,08 hanya pada lembar cetak ke- 1000 (sisi tengah), 1500 (sisi kanan), 2500 (sisi tengah) dan 3500 (sisi kanan) yang nilai densitasnya sama dengan standar, selain dari itu nilainya hanya sebatas toleransi. Pada densitas black dengan standar black 1,68 hanya 
pada lembar cetak ke-1000 (sisi tengah) yang nilai densitas sama dengan standar, selain dari itu nilainya hanya sebatas toleransi bahkan melebihi dari toleransi pada cetakan ke-500 (sisi kanan dan kiri) dengan penyimpangan nilai densitas $-0,12$ dan 0,09, cetakan ke- 1000 (sisi kiri) dengan penyimpangan nilai densitas 0,08 , cetakan ke-1500 (sisi kiri) dengan penyimpangan nilai densitas 0,09, cetakan ke-2000 (sisi kanan) dengan penyimpangan nilai densitas $-0,14$, cetakan ke- 2500 (sisi kiri) dengan penyimpangan nilai densitas 0,08, cetakan ke-3000 (sisi kanan dan kiri) dengan penyimpangan nilai densitas $-0,07$ dan 0,07, cetakan ke-3500 (sisi kiri) dengan penyimpangan nilai densitas 0,09 dan cetakan ke-4000 (sisi kiri) dengan penyimpangan nilai densitas 0,11 . Dengan demikian yang perlu diatur yaitu pada sisi bagian kanan dengan mengatur sedikit penambahan tinta sedangkan pada sisi tengah dan kiri dengan mengurangi pemberian tinta yang diberikan pada cetakan.

Selisih dari hasil pengukuran nilai densitas di atas berfungsi untuk menunjukkan seberapa besar penyebaran nilai densitas yang ada, semakin kecil nilai variannya atau nilai penyebarannya maka warna yang dihasilkan semakin bagus dan terjadinya perbedaan nilai densitas juga mengakibatkan perbedaan warna yang diakibatkan selisih antara hasil cetak pada interval setiap 500 lembar dengan standar. Selisih dari hasil pengukuran nilai densitas juga berguna untuk mengetahui nilai penyimpangan masingmasing warna pada cetakan, dengan begitu perusahaan dapat mengendalikan proses produksi sejak dini. Hal itu dapat berjalan baik apabila dalam perusahaan saling bekerja sama untuk melakukan proses pengendalian produksi serta menjalankan standar-standar yang telah disepakati oleh perusahaan, untuk dapat melakukannya perusahaan harus mampu menyediakan bahan baku yang berkualitas, mesin yang konsisten dalam mencetak, peralatan yang menunjang, pelatihan peningkatan skill karyawan serta membentuk sistem manajemen yang baik. Manfaat dari ini, yaitu perusahaan tentunya akan mendapatkan keuntungan atas kepuasan pelanggan terhadap produk yang sesuai dengan standar dan pelayanan yang diberikan oleh perusahaan.

\section{KESIMPULAN}

Pada densitas cyan dengan standar cyan 1,30 hanya terjadi pada lembar cetak ke500 (sisi kanan), 2500 (sisi tengah), 3500 (sisi tengah dan kiri), dan 4000 (sisi kiri) yang nilai densitasnya sama dengan standar, selain dari itu nilainya hanya sebatas toleransi bahkan 
melebihi dari toleransi pada cetakan ke- 1000 (sisi kiri) dengan penyimpangan nilai densitas 0,09. Densitas magenta dengan standar magenta 1,47 hanya terjadi pada lembar cetak ke- 3500 (sisi kanan) yang nilai densitasnya sama dengan standar, selain dari itu nilainya hanya sebatas toleransi bahkan melebihi dari toleransi pada cetakan ke- 500 (sisi kanan dan tengah) dengan penyimpangan nilai densitas 0,11 dan -0,07, cetakan ke- 1500 (sisi kanan) dengan penyimpangan nilai densitas 0,07. Nilai densitas yellow dengan standar yellow 1,08 hanya pada lembar cetak ke- 1000 (sisi tengah), 1500 (sisi kanan), 2500 (sisi tengah) dan 3500 (sisi kanan) yang nilai densitasnya sama dengan standar, selain dari itu nilainya hanya sebatas toleransi. Pada densitas black dengan standar black 1,68 hanya pada lembar cetak ke-1000 (sisi tengah) yang nilai densitas sama dengan standar, selain dari itu nilainya hanya sebatas toleransi bahkan melebihi dari toleransi pada cetakan ke-500 (sisi kanan dan kiri) dengan penyimpangan nilai densitas 0,12 dan 0,09, cetakan ke- 1000 (sisi kiri) dengan penyimpangan nilai densitas 0,08 , cetakan ke-1500 (sisi kiri) dengan penyimpangan nilai densitas 0,09 , cetakan ke2000 (sisi kanan) dengan penyimpangan nilai densitas -0,14, cetakan ke- 2500 (sisi kiri) dengan penyimpangan nilai densitas 0,08 , cetakan ke-3000 (sisi kanan dan kiri) dengan penyimpangan nilai densitas $-0,07$ dan 0,07 , cetakan ke-3500 (sisi kiri) dengan penyimpangan nilai densitas 0,09 dan cetakan ke-4000 (sisi kiri) dengan penyimpangan nilai densitas 0,11 .

Perbedaan nilai densitas mengakibatkan terjadinya perbedaan warna dalam hasil cetak. Hal ini dapat diketahui jika nilai densitas tinggi maka warna pada hasil cetak akan semakin solid atau gelap karena nilai L* (Lightness) akan turun kecerahannya sementara sebaliknya jika nilai densitas rendah maka warna pada hasil cetak akan pudar atau menipis dan nilai L* (Lightness) akan semakin cerah.

Faktor yang mempengaruhi kualitas hasil cetak ada 4 (empat), yaitu man, machine, material dan methode. Di mana empat komponen tersebut satu sama lainnya sangat berkaitan dan saling menunjang dalam proses kerja produksi. Untuk mendapatkan nilai densitas yang standar dan hasil produk yang berkualitas maka empat faktor tersebut harus terpenuhi dengan baik serta berjalan secara beriringan.

\section{REFERENSI}

Dameria, A. 2008. In Basic Printing Panduan Dasar Cetak untuk Desainer dan Industri Grafika. Jakarta.

Lauw, Efendy. 2013. Color Management. Jakarta.

Majid, Abdul dan Nurjalih. 2018. Pasca 
Vol. 7, No. 2, Oktober 2020, hal. 119-129

Cetak 2. Jakarta: Politeknik Negeri

Media Kreatif Jakarta.

Nurjalih. 2010. Pengetahuan Warna Teknik

Grafika Semester 1. Jakarta: Pusat Grafika Indonesia.

Nursidhi, Agus. 2018. Cetak Datar/Ofset.

Soebardianto. 2017. Bahan Ajar Quality

Control. Jakarta: Politeknik negeri Media kreatif.

Sudiyamto dan Sutiyo. 2011. Dasar Cetak

Ofset. Jakarta: Politeknik Negeri Media Kreatif.

Susanto, A. S. 2013. Indonesian Printing
Industry Trends, Current Technology, and Future Development. Journal of Printing Science and Technology,50(1),hal.046-056.

Wasono, Antonius Bowo. 2008. Teknik Grafika dan Industri Grafika Jilid 1. Direktorat Pembinaan Sekolah Menengah Kejuruan.

Wasono, Antonius Bowo. 2008. Teknik Grafika dan Industri Grafika Jilid 2. Direktorat Pembinaan Sekolah Menengah Kejuruan. Retrieved from 